\title{
Comparative effectiveness of two popular weight loss programs in women II: metabolic markers
}

\author{
Mike Byrd", Michelle Mardock, Brittanie Lockard, Jonathan Oliver, Sunday Simbo, Andrew Jagim, Julie Kresta, \\ C Baetge, Peter Jung, Majid Koozehchian, Deepesh Khanna, Mike Greenwood, Chris Rasmussen, Richard Kreider \\ From International Society of Sports Nutrition: 8th Annual ISSN Conference and Expo \\ Las Vegas, NV, USA. 24-25 June 2011
}

\section{Background}

A number of commercial diet and exercise programs are promoted to help people lose weight and improve fitness. However, few studies have compared the effects of following different types of exercise and diet interventions on weight loss. The purpose of this study was to compare the efficacy of a more structured meal plan based diet intervention and supervised exercise program that included resistance-exercise to a traditional point based diet program with weekly counseling and encouragement to exercise.

\section{Methods}

Fifty-one sedentary women $(35 \pm 8$ yrs, $163 \pm 7 \mathrm{~cm}$; $90 \pm 14 \mathrm{~kg} ; 47 \pm 7 \%$ body fat, $34 \pm 5 \mathrm{~kg} / \mathrm{m}^{2}$ ) were randomized to participate in the Curves (C) or Weight Watchers (W) weight loss programs for 16-weeks. Participants in the $\mathrm{C}$ program were instructed to follow a $1,200 \mathrm{kcal} / \mathrm{d}$ diet for 1 -week, 1,500 kcal/d diet for 3-weeks, and 2,000 kcals/d diet for 2-weeks, consisting of $30 \%$ carbohydrate, $45 \%$ protein, and $30 \%$ fat. Subjects repeated this diet for the 16-week period. Subjects also participated in the Curves circuit style resistance training program 3-days/week and were encouraged to walk at a brisk pace for 30-minutes on non-training days. This program involved performing 30-60 seconds of bi-directional hydraulic-based resistance exercise on 13 machines interspersed with 30-60 seconds of low-impact callisthenic or Zumba dance exercise. Participants in the $\mathrm{W}$ group followed the $\mathrm{W}$ pointbased diet program, received weekly counseling at a local W facility, and were encouraged to increase physical activity. Fasting blood samples were obtained at 0, 4, 10, \& 16 weeks and analyzed by multivariate analysis of

Exercise \& Sport Nutrition Lab. Texas A\&M University, College Station, TX 77843 , USA variance (MANOVA) with repeated measures for changes in triglycerides (TG), total cholesterol (CHL), low density lipoprotein cholesterol (LDL-c), high density lipoprotein cholesterol (HDL-c), the CHL:HDL-C ratio, and blood glucose. Data are presented as percent changes from baseline for the $\mathrm{C}$ and $\mathrm{W}$ groups, respectively, after 4,10 , and 16 weeks.

\section{Results}

MANOVA analysis of fasting lipids data revealed an overall Wilks' Lamda significant time $(\mathrm{p}=0.001)$ and diet $(p=0.03)$ effect with no significant time $x$ diet effect $(p=0.19)$. No significant time $(p=0.72)$ or time $x$ diet $(\mathrm{p}=0.36)$ effects were seen in changes in TG levels $(\mathrm{C}$ $-8.0 \pm 26,-11.7 \pm 18,-2.3 \pm 26$; W $4.0 \pm 25,5.0 \pm 32,7.8 \pm 5 \%$ ); however, an effect of diet was seen with the $C$ group experiencing a greater reduction in TG $(\mathrm{p}=0.06)$. CHL levels $(\mathrm{p}=0.001)$ and LDL-c levels $(\mathrm{p}=0.01)$ decreased in both groups over time with no differences observed between groups in changes in CHL (C -6.1 \pm 11.0 , $-37.9 \pm 25.8,-2.3 \pm 9.5$; W $-6.8 \pm 9.4,-34.2 \pm 27.4,-6.3 \pm 13.0 \%$, $\mathrm{p}=0.53)$ or LDL-c $(\mathrm{C}-6.9 \pm 17.3,-2.7 \pm 13.6,-4.6 \pm 17.2$; W $-5.6 \pm 14.5,-2.8 \pm 19.7,-11.4 \pm 15.9 \%, \mathrm{p}=0.16)$. Changes in HDL-c (C $-2.1 \pm 12.5,3.0 \pm 12.3,5.9 \pm 18.3$; W $-9.5 \pm 11.5$, $\left.-9.5 \pm 12.7,-1.6 \pm 14.6 \%, \mathrm{p}_{q}=0.001\right)$ and the CHL: HDL-C ratio $(\mathrm{C}-1.8 \pm 13.1,-4.0 \pm 10.1,-3.8 \pm 12.2$; W 3.4 \pm 13.4 , $\left.5.3 \pm 12.5,-3.4 \pm 14.2 \%, \mathrm{p}_{q}=0.009\right)$ were greater in the $\mathrm{C}$ group. No significant time $(\mathrm{p}=0.38)$ or time by diet $(\mathrm{p}=0.31)$ effects were seen in changes in blood glucose $(\mathrm{C}$ $-1.9 \pm 13,-0.5 \pm 12,-3.6 \pm 9$; W $1.0 \pm 12,-1.0 \pm 11,0.9 \pm 12 \%$ ).

\section{Conclusion}

Results indicate that 16-wks of participation in the $\mathrm{C}$ and W programs promoted improvements in CHL and LDLc. However, adherence to a more structured meal plan based diet and supervised exercise program promoted 
more favorable changes in TG, HDL-c and the ratio of CHL: HDL-c.

\section{Funding}

Supported by Curves International (Waco, TX)

Published: 7 November 2011

doi:10.1186/1550-2783-8-S1-P1

Cite this article as: Byrd et al:: Comparative effectiveness of two popular weight loss programs in women II: metabolic markers. Journal of the

International Society of Sports Nutrition 2011 8(Suppl 1):P1.

Submit your next manuscript to BioMed Central and take full advantage of:

- Convenient online submission

- Thorough peer review

- No space constraints or color figure charges

- Immediate publication on acceptance

- Inclusion in PubMed, CAS, Scopus and Google Scholar

- Research which is freely available for redistribution

Submit your manuscript at www.biomedcentral.com/submit
Ciomed Central 